\title{
Antibacterial Activity of Extract Obtained from Tridex Procumbens against Different Pathogenic Bacteria
}

\author{
Suryakant, Dr. Sudhanshu Dhar Dwivedi, Sheeraz Ahmad \\ Govt. Science \& commerce Benazeer college Bhopal.
}

\begin{abstract}
Tridex procumbens family Astraceae is highly reputed medicinal tree commonly known as the Coat button. Various tissues of Tridex procumbens have demonstrated positive effects on heart diseases (root bark), dysentery and inflammation (leaves), diabetes (leaf extract), and ulcers. In the present study the antibacterial activity of the methanol, chloroform, ethanol, \& aqueous extract from the leaves of Tridex procumbens was studied using disc diffusion method \& agar well method against pathogenic bacterial strains of Achromobacter, Bacillus, Klebsiella, CoNS (Coagulase negative staphylococcus), Enterobacter, Enterococci, Pseudomonas, Proteus, Staphylococcus aureus, E. coli. Best result showed in all extract against Pseudomonas, Enterococci, S. aureus and Bacillus in a well diffusion method but S. aureus showed highest zone of inhibition in methanol extract. In paper disc method ethanol extract showed best result against Pseudomona sp.
\end{abstract}

Keywords: Tridex procumbens; Pathogenic bacteria; Agar well diffusion method; Disc diffusion method; Inhibition zone;

\section{INTRODUCTION}

According to $\mathbf{s}$ natural plant products may offer a new source of antibacterial agents. In recent years antimicrobial properties of Indian medicinal plants have been increasingly reported (Aswal et al., 1996; Ahmad et al., 1998). Tridex procumbensL.) belongs to family Astraceae, commonly known as Coat button (Hindi), It is medium sized tree growing throughout the forest of India of altitude 1200 meter. It is found all over India, from sub-Himalayan forest, Bengal, central and south India. The different parts of this plant contain number of secondary metabolities, alkaloids, Terpenoids, sterols and essential oils. Various tissues of Tridex procumbens have demonstrated positive effects on heart diseases (root bark) (Kakiuchi et al., 1991), dysentery and inflammation (leaves) (Arul et al., 2005), diabetes (leaf extract) (Kumar et al., 2009), and ulcers (Udupa et al., 1994).

\section{MATERials AND Methods}

\subsection{Collection \& Preparation of Plant Material}

The fresh leaves of Tridex procumbens were collected from the road sides and railways track sides of Bhopal M.P. and major quantity of the plant material was collected from a fields of local village of Bhopal namely SIDIQ GUNG some about $85 \mathrm{kms}$ from Bhopal in the month of December -January, 2015.

1) Extract preparation-: For this practical five types of extract prepared they are-

The leaf are taken and then rinsed in running tap water, few leaves are shade dry in room for 6-7 days and few in oven dry for 4-5 days and then crushed with the help of mortar-pistle and make powder form for different extract preparation which is used for the practical

a) Aqueous and Ethanol Extract: 100gm powder of fresh, shade dry and oven dry leaf was dipped in $400 \mathrm{ml}$ distilled water in a conical flask and left for 7 days with occasional shaking. Filtered off using sterile filter paper (Whattman no. 1) into a clean conical flask. The extracts obtained were then stored in a refrigerator at $4^{\circ} \mathrm{C}$ for antibacterial activity test. ${ }^{(2)}$

b) Methanol Extract: 50gm powder of fresh, shade dry and oven dry leaves sequentially extracted by shaking for 2 hours on Wrist Action Shaker after overnight soaking in $150 \mathrm{ml}$ of relevant solvent. After filtration, samples were rinsed with additional $3 \times 60 \mathrm{ml}$ portions of the solvent. Combined filtrates were dried at room temperature under electric fan. The extracts were stored in the refrigerator at $4^{\circ} \mathrm{C}$ until required ${ }^{\left({ }^{(8)}\right.}$ 


\section{Suryakant et al.}

c) Chloroform Extract: $10 \mathrm{gm}$ powder of fresh, shade dry and oven dry leaf was dipped in $100 \mathrm{ml}$ distilled water in a conical flask and left for 5 days. Filtered off using sterile filter paper (Whattman no. 1) into a clean conical flask. The extracts obtained were then stored in a refrigerator at $4^{\circ} \mathrm{C}$ for antibacterial activity test. ${ }^{(5)}$

\subsection{Test Organism}

Ten Bacterial strain used in the present study (Achromobacter, Bacillus, Klebsiella, CoNS (Coagulase negative staphylococcus), Enterobacter, Enterococci, Pseudomonas, Proteus, Staphylococcus aureus, E. coli.) were obtained from microbiology departments of Gandhji Medical college Bhopal (M.P.). The bacterial species were identified.

\subsection{Screening of Antibacterial Activity}

Screening of antibacterial activity was performed by standard disc diffusion method \& agar well diffusion method.

\subsubsection{Disc Diffusion Method}

The Mueller Hinton agar media pour into presterilized petriplates after solidification $1 \mathrm{ml}$ of bacterial strain was uniformly speeded on agar plates with the help of glass spreader the plates. The sterilized discs were dipped in the plant extract of concentration. The filter paper disc soaked in the plant extract was placed on the surface of the bacteria on agar plates.

\subsubsection{Agar Well Diffusion Method}

Two milliliter of inoculums of each selected bacterium was inoculated into the $45-50{ }^{\circ} \mathrm{C}$, cooled agar \& plated. After 30 minutes three wells approximately 5-6 mm diameter was bored on the medium plate with the help of sterile cork borer. Using a micropipette, $25 \mu$ l of each extracts were added onto each well on all plates. After antibacterial test, the plates were placed in incubator for 24 hrs at $37^{\circ} \mathrm{C}$

\section{RESULT AND DISCUSSION}

\subsection{Result}

In this study four types of plant extract prepared. All extract is used for antibacterial test which include two types of method i.e., paper disc method and well diffusion method and in this study the practical was done triplet.

\subsection{Paper Disc Method for Leaves Extract}

Table1. Antibacterial activity of Aqueous and Ethanol extract of Tridex procumbens in paper disc method $($ Mean $\pm S D)(\mathrm{mm})$

\begin{tabular}{|l|l|l|l|l|l|l|}
\hline \multirow{2}{*}{ Bacteria } & \multicolumn{2}{|c|}{ Aqueous extract } & \multicolumn{2}{c|}{ Ethanol extract } \\
\cline { 2 - 7 } & Fresh & Shade dry & Oven dry & Fresh & Shade dry & Oven dry \\
\hline Bacillus & $16 \pm 0.3$ & $14 \pm 0.8$ & $11 \pm 0.6$ & $18 \pm 0.2$ & $16 \pm 0.1$ & $14 \pm 0.4$ \\
\hline Proteus & $20 \pm 0.8$ & $18 \pm 0.3$ & $16 \pm 0.2$ & $21 \pm 0.1$ & $19 \pm 0.7$ & $15 \pm 0.7$ \\
\hline Pseudomonas & $25 \pm 0.8$ & $17 \pm 0.2$ & $14 \pm 0.4$ & $25 \pm 0.1$ & $20 \pm 0.6$ & $15 \pm 0.2$ \\
\hline Achromobacter & $21 \pm 0.7$ & $17 \pm 0.3$ & $13 \pm 0.3$ & $23 \pm 0.2$ & $12 \pm 0.1$ & $11 \pm 0.2$ \\
\hline S.aureus & $19 \pm 0.1$ & $0.0 \pm 0.0$ & $15 \pm 0.5$ & $20 \pm 0.7$ & $10 \pm 0.1$ & $0.0 \pm 0.0$ \\
\hline CoNS & $20 \pm 0.3$ & $17 \pm 0.1$ & $16 \pm 0.3$ & $21 \pm 0.2$ & $17 \pm 0.3$ & $16 \pm 0.6$ \\
\hline Enterococci & $24 \pm 0.9$ & $20 \pm 0.1$ & $16 \pm 1.3$ & $26 \pm 0.4$ & $24 \pm 0.8$ & $20 \pm 0.4$ \\
\hline Klebsiella & $20 \pm 0.7$ & $13 \pm 0.8$ & $10 \pm 1.5$ & $22 \pm 0.3$ & $18 \pm 0.8$ & $15 \pm 0.5$ \\
\hline Enterobacter & $21 \pm 0.4$ & $13 \pm 0.7$ & $15 \pm 0.2$ & $21 \pm 0.1$ & $16 \pm 0.8$ & $18 \pm 0.1$ \\
\hline E.coli & $21 \pm 0.14$ & $19 \pm 0.9$ & $18 \pm 0.3$ & $18 \pm 0.4$ & $23 \pm 0.7$ & $16 \pm 0.5$ \\
\hline
\end{tabular}

Table2. Antibacterial activity of Methanol and Chloroform extract of Tridex procumbensin paper disc method $($ Mean $\pm S D)(\mathrm{mm})$

\begin{tabular}{|l|l|l|l|l|l|l|}
\hline \multirow{2}{*}{ Bacteria } & \multicolumn{2}{|c|}{ Methanol extract } & \multicolumn{2}{c|}{ Chloroform extract } \\
\cline { 2 - 7 } & Fresh & Shade dry & Oven dry & Fresh & Shade dry & Oven dry \\
\hline Bacillus & $20 \pm 0.4$ & $16 \pm 0.8$ & $12 \pm 1.7$ & $17 \pm 0.6$ & $14 \pm 0.4$ & $12 \pm 0.8$ \\
\hline Proteus & $24 \pm 0.2$ & $17 \pm 0.5$ & $15 \pm 0.9$ & $18 \pm 0.9$ & $15 \pm 0.1$ & $0.0 \pm 0.0$ \\
\hline Pseudomonas & $23 \pm 0.8$ & $17 \pm 0.3$ & $14 \pm 0.4$ & $20 \pm 0.2$ & $20 \pm 0.7$ & $17 \pm 0.6$ \\
\hline Achromobacter & $19 \pm 0.3$ & $18 \pm 0.8$ & $15 \pm 0.5$ & $18 \pm 1.2$ & $15 \pm 0.9$ & $14 \pm 0.4$ \\
\hline
\end{tabular}


Antibacterial Activity of Extract Obtained from Tridex Procumbens against Different Pathogenic Bacteria

\begin{tabular}{|l|l|l|l|l|l|l|}
\hline \hline S.aureus & $23 \pm 0.3$ & $22 \pm 0.6$ & $14 \pm 0.9$ & $18 \pm 0.2$ & $22 \pm 1.3$ & $15 \pm 0.1$ \\
\hline CoNS & $20 \pm 0.8$ & $17 \pm 0.4$ & $13 \pm 0.3$ & $19 \pm 0.9$ & $16 \pm 0.4$ & $14 \pm 0.1$ \\
\hline Enterococci & $26 \pm 0.9$ & $24 \pm 0.7$ & $20 \pm 0.3$ & $23 \pm 0.4$ & $20 \pm 0.7$ & $19 \pm 0.1$ \\
\hline Klebsiella & $22 \pm 1.4$ & $19 \pm 0.1$ & $13 \pm 0.3$ & $18 \pm 1.1$ & $13 \pm 0.6$ & $11 \pm 0.5$ \\
\hline Enterobacter & $21 \pm 0.3$ & $17 \pm 0.7$ & $13 \pm 0.5$ & $20 \pm 1.9$ & $17 \pm 0.5$ & $15 \pm 0.7$ \\
\hline E.coli & $20 \pm 0.7$ & $18 \pm 0.5$ & $20 \pm 0.9$ & $19 \pm 0.5$ & $16 \pm 0.2$ & $15 \pm 0.8$ \\
\hline
\end{tabular}

The antibacterial activity of aqueous, chloroform, ethanol, and methanol extract of Tridex procumbensleaf were studied by paper disc diffusion method.

\subsubsection{Ethanol Extract}

The result clearly showed in ethanol leaf extract of Tridex procumbens. This extract showed highest zone of inhibition against Pseudomonas, Enterococci, Achromobacter, Klebsiella, Enterobacter, Proteus, In fresh leaf extract $(25 \pm 0.1),(26 \pm 0.4),(23 \pm 0.2),(22 \pm 0.3),(21 \pm 0.1),(21 \pm 0.1)$ respectively. In shade dry leaf extract $(20 \pm 0.6),(24 \pm 0.8),(12 \pm 0.1),(18 \pm 0.8),(16 \pm 0.8),(19 \pm$ $0.7)$ resp. In oven dry leaf extract $(15 \pm 0.2),(20 \pm 0.4),(11 \pm 0.2),(15 \pm 0.5),(18 \pm 0.1),(15 \pm 0.7)$ resp.

\subsubsection{Aqueous Extract}

The result clearly showed in ethanol leaf extract of Tridex procumbens. This extract showed highest zone of inhibition against Pseudomonas, Enterococci, Achromobacter, Klebsiella, Enterobacter, Proteus, In fresh leaf extract $(25 \pm 0.8),(24 \pm 0.9),(21 \pm 0.7),(20 \pm 0.7),(21 \pm 0.4),(20 \pm 0.8)$ respectively. In shade dry leaf extract $(17 \pm 0.2),(20 \pm 0.1),(17 \pm 0.3),(13 \pm 0.8),(13 \pm 0.7),(18 \pm$ $0.3)$ resp. In oven dry leaf extract $(14 \pm 0.4),(16 \pm 1.3),(13 \pm 0.3),(10 \pm 1.5),(15 \pm 0.2),(16 \pm 0.2)$ resp.

\subsubsection{Methanol Extract}

The result clearly showed in ethanol leaf extract of Tridex procumbens . This extract showed highest zone of inhibition against Pseudomonas, Enterococci, Achromobacter, Klebsiella, Enterobacter, Proteus, In fresh leaf extract $(23 \pm 0.8),(26 \pm 0.9),(19 \pm 0.3),(22 \pm 1.4),(21 \pm 0.3),(24 \pm 0.2)$ respectively. In shade dry leaf extract $(17 \pm 0.3),(24 \pm 0.7),(18 \pm 0.8),(19 \pm 0.1),(17 \pm 0.7),(17 \pm$ $0.5)$ resp. In oven dry leaf extract $(14 \pm 0.4),(20 \pm 0.3),(15 \pm 0.5),(13 \pm 0.3),(13 \pm 0.5),(15 \pm 0.9)$ resp.

\subsubsection{Chloroform Extract}

The result clearly showed in ethanol leaf extract of Tridex procumbens. This extract showed highest zone of inhibition against Pseudomonas, Enterococci, Achromobacter, Klebsiella, Enterobacter, Proteus, In fresh leaf extract $(20 \pm 0.2),(23 \pm 0.4),(18 \pm 1.2),(18 \pm 1.1),(20 \pm 1.9),(18 \pm 0.9)$ respectively. In shade dry leaf extract $(20 \pm 0.7),(20 \pm 0.7),(15 \pm 0.9),(13 \pm 0.6),(17 \pm 0.5),(15 \pm$ $0.1)$ resp. In oven dry leaf extract $(17 \pm 0.6),(19 \pm 0.1),(14 \pm 0.4),(11 \pm 0.5),(15 \pm 0.7),(0.0 \pm 0.0)$ resp.

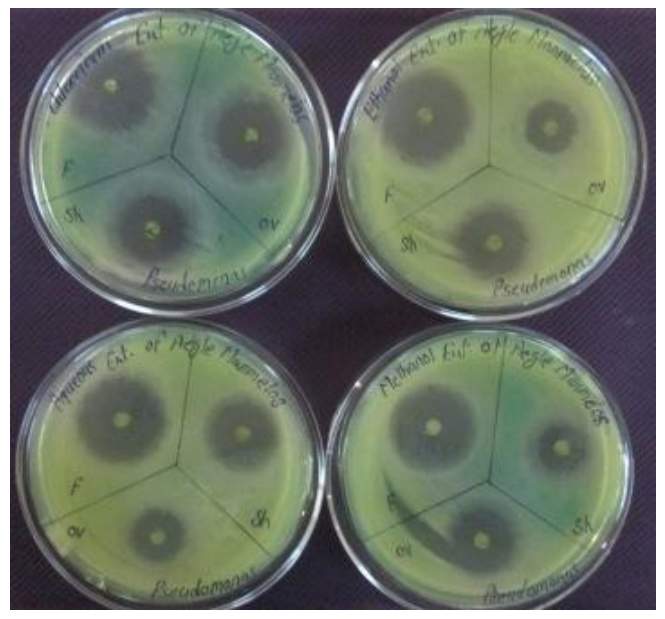

Fig1. Zone of inhibition of Pseudomonas

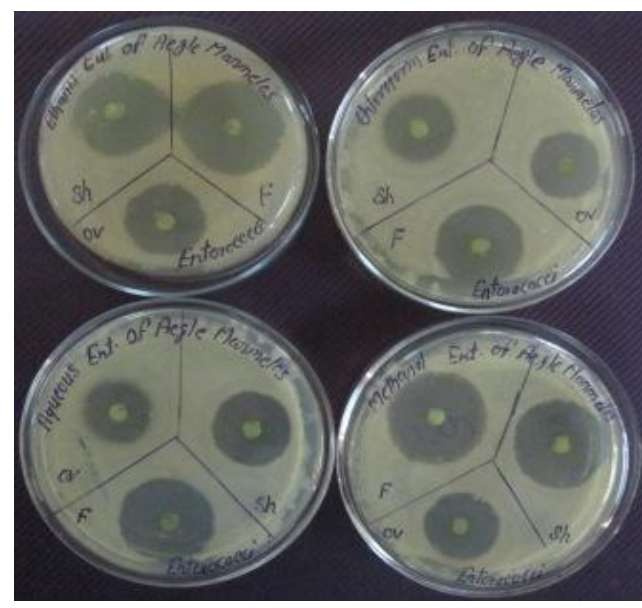

Fig2. Zone of inhibition of Enterococci 
Suryakant et al.

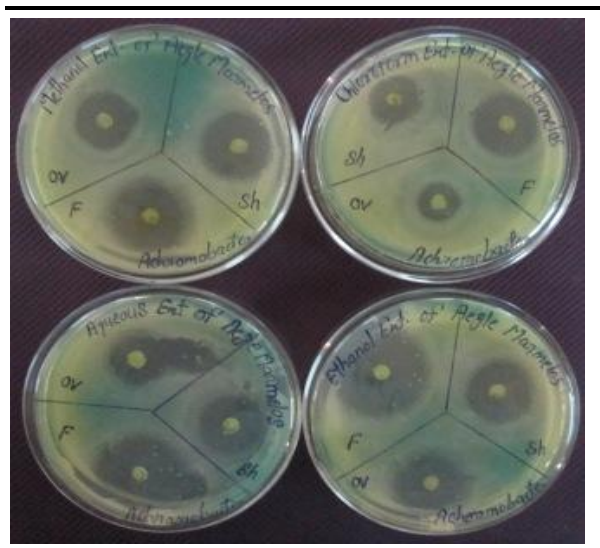

Fig3. Zone of inhibition of Achromobacter

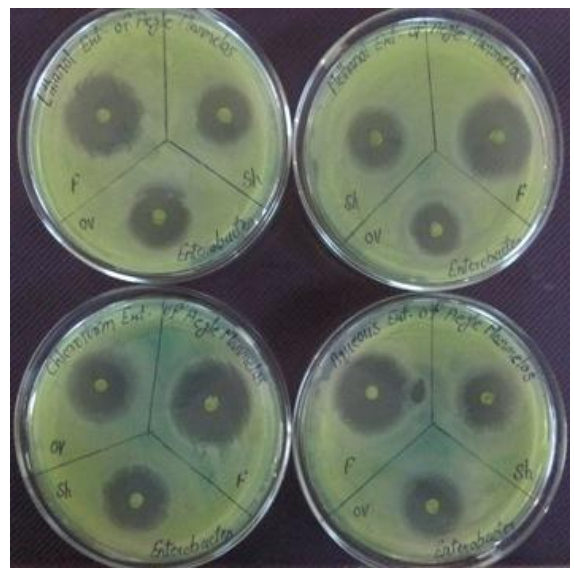

Fig5. Zone of inhibition of Enterobacter

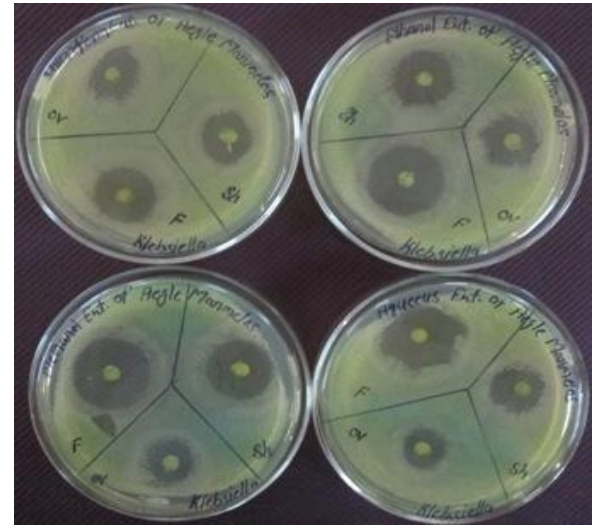

Fig4. Zone of inhibition of Klebsilla

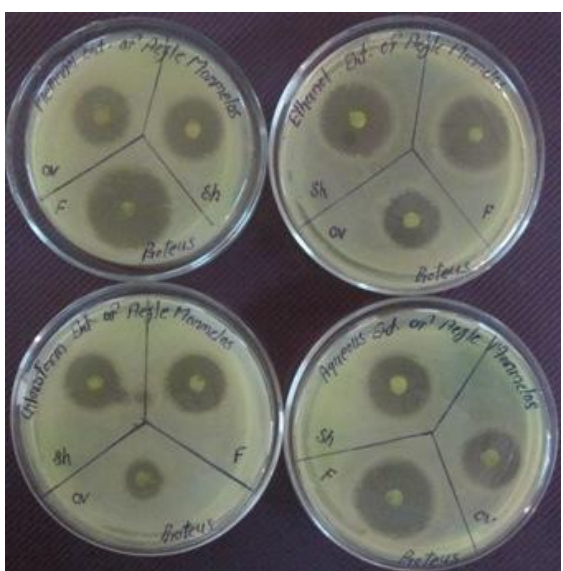

Fig6. Zone of inhibition of Proteus

Fig. Zone of Inhibition of Leaf extract against human pathogenic bacteria

\subsection{Well Diffusion Method for Leaves Extract}

Table3. Antibacterial activity of Aqueous and Methanol extract of Tridex procumbens in Agar well diffusion method (Mean $\pm S D)(\mathrm{mm})$

\begin{tabular}{|l|l|l|l|l|l|l|}
\hline \multirow{2}{*}{ Bacteria } & \multicolumn{2}{|c|}{ Aqueous extract } & \multicolumn{2}{c|}{ Methanol extract } \\
\cline { 2 - 7 } & Fresh & Shade dry & Oven dry & Fresh & Shade dry & Oven dry \\
\hline Bacillus & $14 \pm 0.3$ & $15 \pm 0.8$ & $14 \pm 0.1$ & $21 \pm 0.6$ & $20 \pm 0.9$ & $14 \pm 0.7$ \\
\hline Proteus & $17 \pm 0.4$ & $14 \pm 0.7$ & $0.0 \pm 0.0$ & $25 \pm 0.1$ & $19 \pm 0.7$ & $20 \pm 0.5$ \\
\hline Pseudomonas & $15 \pm 0.9$ & $15 \pm 0.4$ & $13 \pm 0.6$ & $22 \pm 0.3$ & $15 \pm 0.6$ & $14 \pm 0.7$ \\
\hline Achromobacter & $16 \pm 1.1$ & $13 \pm 0.4$ & $11 \pm 0.7$ & $17 \pm 0.3$ & $13 \pm 0.8$ & $0.0 \pm 0.0$ \\
\hline S.aureus & $18 \pm 0.7$ & $15 \pm 0.5$ & $14 \pm 0.7$ & $24 \pm 0.4$ & $19 \pm 0.9$ & $20 \pm 0.4$ \\
\hline CoNS & $13 \pm 0.6$ & $0.0 \pm 0.0$ & $0.0 \pm 0.0$ & $14 \pm 0.9$ & $10 \pm 0.5$ & $0.0 \pm 0.0$ \\
\hline Enterococci & $21 \pm 0.9$ & $16 \pm 0.1$ & $11 \pm 1.3$ & $21 \pm 0.2$ & $20 \pm 0.3$ & $13 \pm 0.9$ \\
\hline Klebsiella & $13 \pm 0.7$ & $11 \pm 0.8$ & $0.0 \pm 0.0$ & $15 \pm 0.3$ & $13 \pm 0.8$ & $11 \pm 0.5$ \\
\hline Enterobacter & $19 \pm 0.7$ & $12 \pm 0.7$ & $0.0 \pm 0.0$ & $21 \pm 0.9$ & $19 \pm 0.5$ & $17 \pm 0.4$ \\
\hline E.coli & $17 \pm 0.4$ & $14 \pm 0.9$ & $0.0 \pm 0.0$ & $20 \pm 0.9$ & $15 \pm 0.6$ & $0.0 \pm 0.0$ \\
\hline
\end{tabular}

Table4. Antibacterial activity of Ethanol and Chloroform extract of Tridex procumbens in Agar well diffusion method (Mean $\pm S D)(\mathrm{mm})$

\begin{tabular}{|l|l|l|l|l|l|l|}
\hline \multirow{2}{*}{ Bacteria } & \multicolumn{2}{|c}{ Chloroform } & \multicolumn{2}{c|}{ Ethanol extract } \\
\cline { 2 - 7 } & Fresh & Shade dry & Oven dry & Fresh & Shade dry & Oven dry \\
\hline Bacillus & $20 \pm 0.7$ & $18 \pm 0.3$ & $9 \pm 0.3$ & $23 \pm 0.1$ & $18 \pm 0.7$ & $16 \pm 0.8$ \\
\hline Proteus & $18 \pm 0.3$ & $14 \pm 0.7$ & $0.0 \pm 0.0$ & $18 \pm 0.9$ & $16 \pm 0.4$ & $0.0 \pm 0.0$ \\
\hline Pseudomonas & $15 \pm 0.1$ & $14 \pm 0.5$ & $11 \pm 0.8$ & $18 \pm 0.8$ & $14 \pm 0.4$ & $12 \pm 0.9$ \\
\hline Achromobacter & $14 \pm 0.3$ & $12 \pm 0.9$ & $11 \pm 0.7$ & $19 \pm 0.3$ & $17 \pm 0.6$ & $10 \pm 0.9$ \\
\hline S.aureus & $15 \pm 0.9$ & $15 \pm 0.2$ & $14 \pm 0.4$ & $20 \pm 0.5$ & $18 \pm 0.5$ & $20 \pm 0.1$ \\
\hline CoNS & $9 \pm 0.8$ & $0.0 \pm 0.0$ & $0.0 \pm 0.0$ & $14 \pm 0.2$ & $12 \pm 0.7$ & $10 \pm 0.4$ \\
\hline Enterococci & $22 \pm 0.7$ & $20 \pm 0.1$ & $0.0 \pm 0.0$ & $23 \pm 0.9$ & $21 \pm 0.4$ & $15 \pm 0.4$ \\
\hline Klebsiella & $11 \pm 0.8$ & $9 \pm 0.4$ & $9 \pm 0.8$ & $13 \pm 0.3$ & $10 \pm 0.6$ & $9 \pm 0.7$ \\
\hline Enterobacter & $17 \pm 0.7$ & $20 \pm 0.2$ & $6 \pm 0.3$ & $18 \pm 0.8$ & $17 \pm 0.2$ & $8 \pm 0.3$ \\
\hline E.coli & $19 \pm 0.4$ & $19 \pm 0.9$ & $0.0 \pm 0.0$ & $21 \pm 0.6$ & $19 \pm 0.5$ & $20 \pm 0.9$ \\
\hline
\end{tabular}


The antibacterial activity of aqueous, chloroform, ethanol, and methanol extract of Tridex procumbens leaf were studied by agar well diffusion method.

\subsubsection{Aqueous Extract}

The result clearly showed in ethanol leaf extract of Tridex procumbens . This extract showed highest zone of inhibition against Enterococci, Pseudomonas, S. aureus, Bacillus, in fresh leaf extract $(21 \pm$ $0.9),(15 \pm 0.9),(18 \pm 0.7),(14 \pm 0.3)$ respectively. In shade dry leaf extract $(16 \pm 0.1),(15 \pm 0.4),(15$ $\pm 0.5),(15 \pm 0.8)$ resp. In oven dry leaf extract $(11 \pm 1.3),(13 \pm 0.6),(14 \pm 0.7),(14 \pm 0.1)$ resp.

\subsubsection{Methanol Extract}

The result clearly showed in ethanol leaf extract of Tridex procumbens . This extract showed highest zone of inhibition against Enterococci, Pseudomonas, S. aureus, Bacillus, in fresh leaf extract (21 \pm $0.2),(22 \pm 0.3),(24 \pm 0.4),(21 \pm 0.6)$ respectively. In shade dry leaf extract $(20 \pm 0.3),(15 \pm 0.6),(19$ $\pm 0.9),(20 \pm 0.9)$ resp. In oven dry leaf extract $(13 \pm 0.9),(14 \pm 0.7),(20 \pm 0.4),(14 \pm 0.7)$ resp.

\subsubsection{Chloroform Extract}

The result clearly showed in ethanol leaf extract of Tridex procumbens . This extract showed highest zone of inhibition against Enterococci, Pseudomonas, S. aureus, Bacillus. In fresh leaf extract (22 \pm $0.7),(15 \pm 0.1),(15 \pm 0.9),(20 \pm 0.7)$ respectively. In shade dry leaf extract $(20 \pm 0.1),(14 \pm 0.5),(15$ $\pm 0.2),(18 \pm 0.3)$ resp. In oven dry leaf extract $(0.0 \pm 0.0),(11 \pm 0.8),(14 \pm 0.4),(9 \pm 0.3)$ resp.

\subsubsection{Ethanol Extract}

The result clearly showed in ethanol leaf extract of Tridex procumbens. This extract showed highest zone of inhibition against Enterococci, Pseudomonas, S. aureus, Bacillus. In fresh leaf extract (23 \pm $0.9),(18 \pm 0.8),(20 \pm 0.5),(23 \pm 0.1)$, respectively. In shade dry leaf extract $(21 \pm 0.4),(14 \pm 0.4)$, $(18 \pm 0.5),(18 \pm 0.7)$ resp. In oven dry leaf extract $(15 \pm 0.4),(12 \pm 0.9),(20 \pm 0.1),(16 \pm 0.8)$ resp.

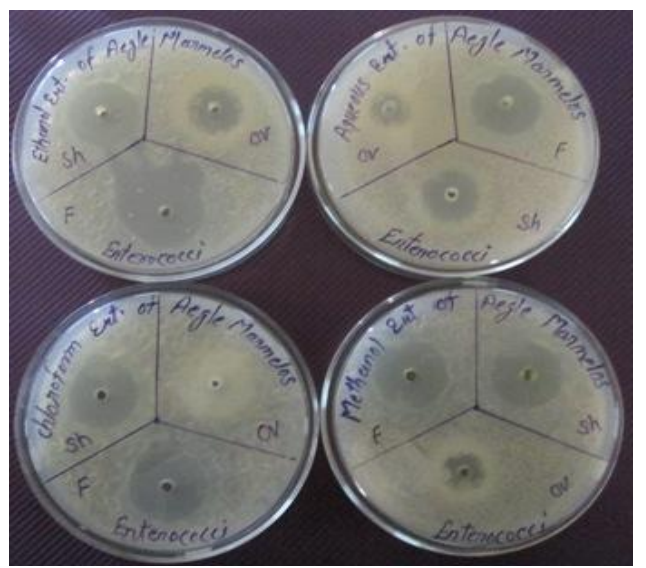

Fig7. Zone of inhibition of Enterococci

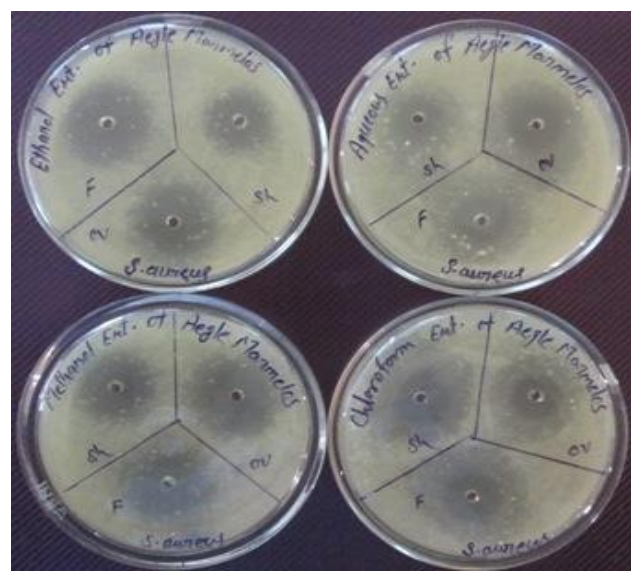

Fig9. Zone of inhibition of S.aureus

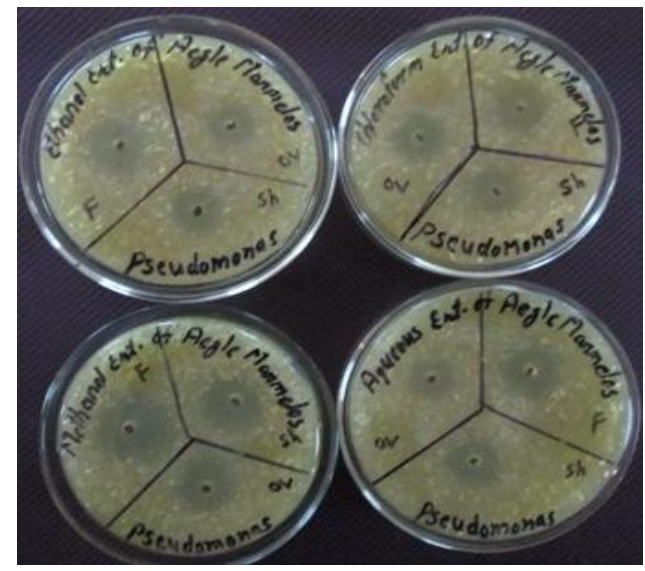

Fig8. Zone of inhibition of Pseudomonas

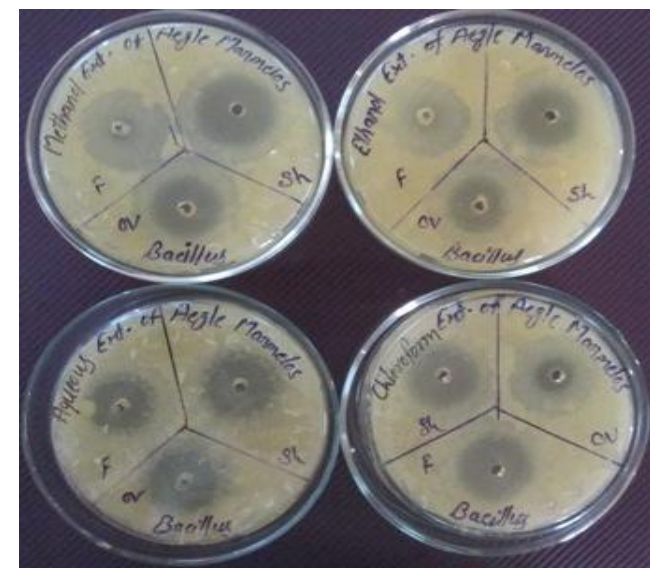

Fig10. Zone of inhibition of Bacillus

Fig. Zone of Inhibition of Leaf extract against human pathogenic bacteria 


\section{DISCUSSION}

According to (D.Venhatsan, and M. Karunakaran, 2009) the antibacterial activity of Tridex procumbens extract of both solvents Aqueous and ethanolic against different pathogenic bacteria by paper disc method. The ethanolic extract showed considerably more activity compare than the aqueous extract. Maximum antibacterial activity was shown against Pseudomonas sp. compare than other bacteria. In this present study ethanolic \& aqueous leaf extract of Tridex procumbens against different pathogenic bacteria. The result clearly showed that ethanol extracts of these plants were certainly much better and powerful against Pseudomonas (in fig 1). According to (Saroj Kothari, and Savita Bharat , 2011) Tridex procumbens leaf extracts of both solvents chloroform \& methanol showed good result in antimicrobial activities against Pseudomonas, Klebsiella sp. by paper disc method. The chloroform leaf extract showed considerably more activity than the methanolic extract. But in present study methanol leaf extract of Tridex procumbens shows best result against Pseudomonas, and Klebsiella sp. compare than chloroform extract.

According to (M. Poonkothai, M. Saravanan, 2007), the best result showed in aqueous extract against Bacillus sp. campare than other extract and other bacteria in well diffusion method. In present study the best result showed in all extract against Pseudomonas, Enterococci, S. aureus and Bacillus but $S$. aureus (in fig 9) showed highest zone of inhibition in methanol extract. The leaf extracts of Tridex procumbens to inhibit growth of bacteria is an indication of its broad spectrum antibacterial activity, which may be employed as a source to develop new antimicrobial agents.

\section{REFERENCES}

[1] Aswal, B. S., Goel, A. K. and Patneik, G .K. (1996). Screening of Indian medicinal plants for biological activity. Indian J. Exptal. Biol. 34: $444-467$.

[2] Akueshi, C.O., Kadiri, E. U. Akueshi, S. E. Agina, and B. Ngurukwem. 2002. Antimicrobial potentials of Hyptis sauvedens Poit (Lamiaccae). J. Bot. 15: 37-41.

[3] D. Venkatesan, (2009). Antimicrobial Activity of Tridex procumbens Against Pathogenic Organism Compared with Control Drug, Ethnobotanical Leaflets 13: 968-74.

[4] Kakiuchi, N., L.R. Senaratne, S.L. Huang, X.W. Yang, M. Hattori, U. Pilapitiya, and T. Namba. 1991. Effects of constituents of Beli (Aegle marmelos) on spontaneous beating and calciumparadox of myocardial cells. Planta Med. 57:43-46.

[5] Kareem, S. O. Akpan, I. and Ojo, O. P (2008). Antimicrobial Activities of Calotropis procera on Selected Pathogenic Microorganisms. African Journal of Biomedical Research, Vol. 11.

[6] Mukesh Pimpliskar, et al (2012). Antibacterial screening of stem, fruit and leaves of A. marmelos, European Journal of Zoological Research,, Vol. 1 (2):60-64.

[7] Saroj Kothari, et al. (2011), Antimicrobial Activity and Phytochemical Screening Of Serial Extracts From Leaves of Tridex procumbens, Acta Poloniae Pharmaceutica ñ Drug Research, Vol. 68 No. 5 pp. 687-692.

[8] Sunday E. Atawodi (2005). Comparative in vitro trypanocidal activities of petroleum ether, chloroform, methanol and aqueous extracts of some Nigerian savannah plants, African Journal of Biotechnology Vol. 4 (2), pp. 177-182.

[9] Udupa, S.L., A.L. Udupa, and D.R. Kulkarni. 1994. Studies on the anti-inflammatory and wound healing properties of Moringa oleifera and Aegle marmelos. Fitoterpia 65:119 123. 